\title{
Concept of a Composite Frame of Martian Vehicle
}

\author{
Damian Markuszewski ${ }^{*}$, Mariusz Wądołowski', Michał Gorzym¹, Michał Bielak ${ }^{1}$ \\ 1 Faculty of Automotive and Construction Machinery Engineering, Warsaw University of Technology, ul. \\ Narbutta 84, 02-524 Warszawa, Poland \\ * Corresponding author's e-mail: denmarks@o2.pl
}

\begin{abstract}
The presented article describes the design and strength analysis of the frame of the Mars rover, which will start in the European Rover Challenge. The shape of the frame is determined by the six-wheeled rocker-bogie suspension chosen for the project, which is characterized by high stability and even distribution of wheel pressure on the ground and a reduction in the vibration frequency of the frame in which the vehicle electronics are located. The adopted slants counteract the swinging frame on the suspension, which has been checked by kinematic analysis. The design uses the concept of a frame structure made of sandwich walls, consisting of: 3D printed elements - an openwork grille with a honeycomb structure, a low-pressure foam filler and a carbon composite made of a combination of three layers of carbon fiber mat with a 1z1 weave and 0/45/90 orientation with Epidian 5 epoxy resin ensuring equal spacing between the layers. Such a combination of materials allowed for a very durable and light structure with a significant reduction in weight compared to the original concept - an aluminum frame. A "cross"-shaped support element was also used, connecting the upper part of the frame with the lower one - also made in the 3D printing technique, which is also a link between the frame and suspension. The analysis showed that the materials and sections of structural elements adopted for the project are appropriate for the assumed load. In the case of unloading from the manipulator, the authors proposed to increase the safety factor due to the possibility of an additional load from dynamic forces. In places where reduced stresses reach increased values, additional reinforcements are provided.
\end{abstract}

Keywords: MES, martian vehicle, composite frame

\section{INTRODUCTION}

In recent years, human activity in the field of unmanned space flights and the return to the idea of space exploration have noticeably increased. The main goal of this activity is to prepare a manned flight to yet another planet unconquered by man - Mars. The difficulty of an unmanned mission stems from the inability to intervene or correct the equipment sent and from a considerable delay in performing control over long distances. The preparation of such a mission requires predicting possible malfunctions, applying autonomous control and a high level of precision. The main element of such a mission is a probe, or more specifically, a vehicle exploring the planet and providing support for the work of astronauts in the future.
The first vehicle of this kind was the Lunokhod, a rover designed by Soviet scientists and sent to the Moon in the 1970s. Prof. Mieczysław Bekker, co-creator of the Lunar Roving Vehicle (LRV) used in the Apollo 15 mission was the Polish pioneer in this field.

If one takes a look at the history of design solutions, it becomes apparent that there is a significant increase in the weight and size of rovers and the number of tasks they are expected to perform. Undoubtedly, they are very complicated technical devices, constituting the pinnacle of human technical thought.

One of the rover's primary tasks is to produce an engineering set and send the results back to Earth. This set is composed of photos and videos from cameras, and results from the investigations of the magnetic field, atmosphere and geology. 
For this purpose, the vehicle travels over short distances at a low speed. During its trips, it has to negotiate uneven surfaces, rocks and chasms. Such journeys require high stability of the construction, which is ensured by: low placement of the centre of gravity and maximisation of the axle base and wheelbase. The designers of such vehicles have to face often contradictory assumptions.

The gravitational field on Mars is three times smaller than on Earth, and the forces acting on the vehicle are also three times smaller. On the other hand, the rover has to withstand the forces during the rocket launch, which leads to the vehicle's greater strength and extended longevity. Another challenge is the substrate, the medium on which the rover rides - it is extremely fine sand in which the vehicle may get stuck, as it happened in the case of the Spirit rover [19]. Tires should have a sufficiently large surface area, but at the same time, rolling resistance increases the consumption of electricity, which is a highly valuable resource. Although clouds on Mars are rare and the atmosphere is clear, frequent dust storms reduce the effectiveness of solar panels. The most recent designs employed a radioisotope thermoelectric generator as the primary power source. Limited energy resources necessitate the selection of energy-efficient actuators. Another threat comes from the high-energy space particles, which pose a danger to electrical systems. Due to the delay in the transmission of radio waves, designers strive to ensure as much autonomous control as possible. Application of composite materials allows for better optimization of the shape and weight, which might improve the vehicle's functionality and the light laminate structure is less sensitive magnetically.

\section{Frame design}

The frame presented in the article was designed for a Martian rover taking part in the European Rover Challenge competition. For the sake of stability, a six-wheel rocker-bogie suspension was selected for the design (Fig. 1). By definition, a "double tripod" is more stable than the standard suspension of a four-wheeled off-road vehicle. Additional advantages of such a suspension include evenly distributed pressure of the wheels on the ground and reduction of the frequency of vibrations in the frame where the vehicle electronic components are located. This effect was achieved by a pivoting mounting of the frame in relation to two support points -1 and 2 (Fig.2).

The ERC competition takes place in terrestrial conditions, on a specially prepared track, so the rover's structure has to be characterised by greater strength. During the competition, the Martian rover has to compete in 5 tasks [18]:

- Science Task - soil sampling, e.g., by drilling and securing samples for analysis,

- Maintenance Task - travelling the path to the control panel and performing a series of manual operations,

- Collection Task - localizing and collecting containers with the samples and delivering them to a designated point,

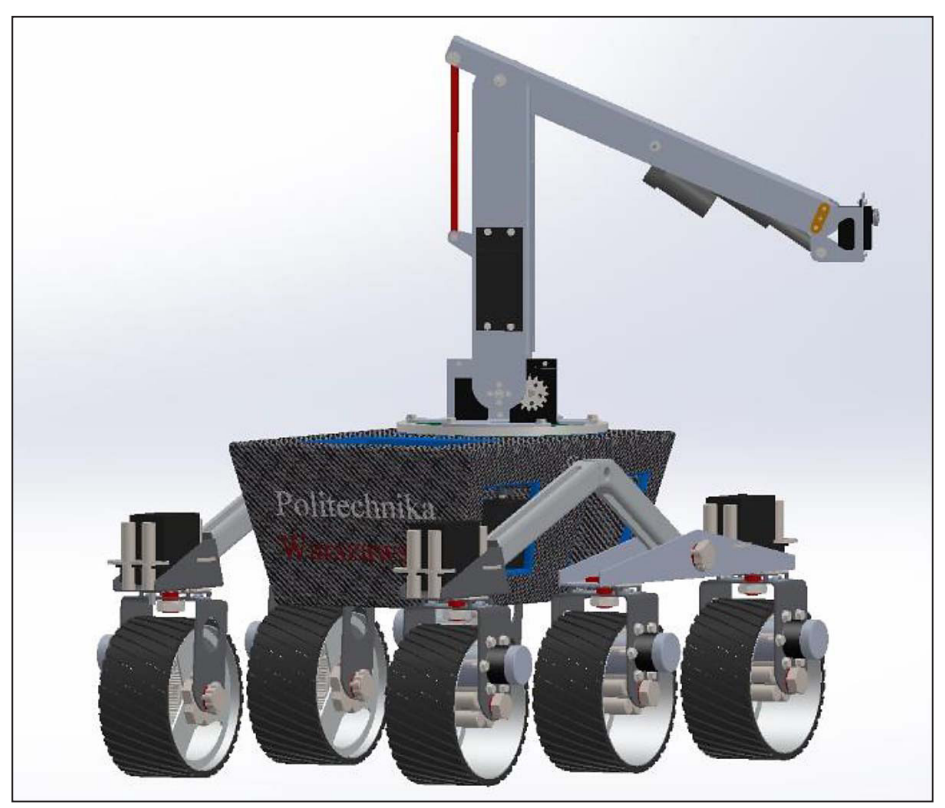

Fig. 1. The prototype of a Martian rover [6] [13] 
- Traverse Task - finding points placed along the track without using a camera; the vehicle uses an autonomous mode based on the map,

- Presentation Task - presentation of the stages in the development of the rover.

The main load for the vehicle's structure is a $9 \mathrm{~kg}$ manipulator and a $7.5 \mathrm{~kg}$ battery. The manipulator was designed in accordance with the rules applicable in America, where the final competition takes place, i.e., minimum load capacity of $5 \mathrm{~kg}$. This led to using a larger manipulator than it would seem necessary in the context of the European version of the ERC competition. A decision was made to design a box-type frame, which allows for achieving appropriate rigidity, and protecting the control electronics elements against external factors while maintaining adequate ventilation. Such a design allows for an easy installation of a manipulator and a drilling tower for the purpose of collecting an $8 \mathrm{~kg}$ soil sample. In addition, an opening was made in the front part of the top panel to allow the actuators of the manipulator to be installed inside the turntable (lazy Suzy bearings), to lower the centre of gravity as much as possible. This contributes considerably to the stability of the vehicle. The rules establish a system of bonuses and point penalties. Rovers weighing less than $50 \mathrm{~kg}$ receive bonus points, while rovers with a weight range of $50 \div$ $60 \mathrm{~kg}$ do not receive them, and rovers weighing above $60 \mathrm{~kg}$ receive penalty points.

Weight optimization is very costly and requires high-tech materials. A frame with walls made of sandwich was selected (Fig. 3): three 0/45/90 oriented carbon fibre mats, a honeycomb structure made using the 3D printing technology, filled with foam and a closing layer - three $0 / 45 / 90$ oriented carbon

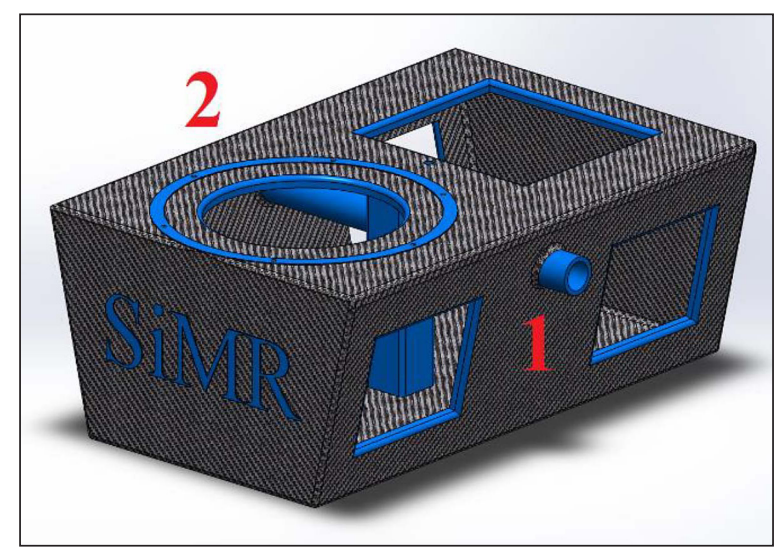

Fig. 2. Composite frame fibre mats. Individual elements are glued together. The first inner layer was made using the manual lamination technique in a mould with a filling ratio of Epidian 5 resin and carbon fibre reinforcement with a single weave of $200 \mathrm{~g} / \mathrm{m}^{2}$ in a $50 / 50$ ratio. This resulted in a very smooth inner surface.

The next stage consists in gluing the hexagonal honeycomb structure [8] made of PLA (polylactic acid) material to the previously prepared inner layer and filling the voids with foam. After removing the excess foam, the outer layer, made in the same technique as the inner layer, is glued onto it. The last stage is to glue the top wall to the box frame and make the holes according to the design.

The design of the Martian rover's frame was prepared within the budget of KN Bekker Team. Due to limited resources, it was not possible to use other manufacturing technologies: Resin Transfer Moulding or Vacuum Assisted Resin Transfer Moulding. Three different hexagonal honeycomb structures with a $1 \mathrm{~mm}$ thick wall and appropriately inscribed circles were used (Fig. 4). Structure A was used for the top layer, to which the manipulator will be attached. Structure B was used for the side walls, which are both load-bearing walls and connectors with the suspension. Structure $\mathrm{C}$ was used for the front and back walls, and for the floor bearing a lighter load, on which the electronics are placed.

Additionally, a "cross brace" support element is used to connect the upper layer, the lower layer and the beam - a suspension element (Fig. 5). This element is the support for the differential mechanism (rocker-bogie suspension). The beam element, connecting the right and left suspension, consists of an aluminium tube of Ø20 mm with a wall thickness of $2 \mathrm{~mm}$, and a sleeve made using 3D printing technology from PLA material with a

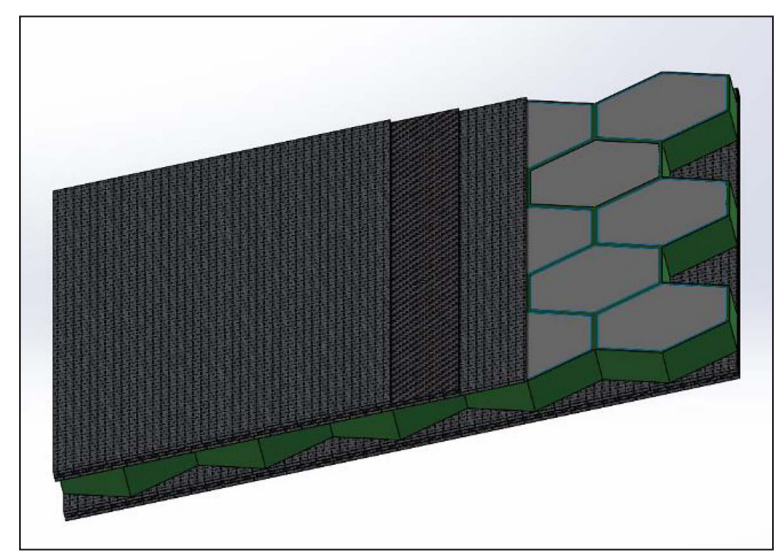

Fig. 3. Sandwich 


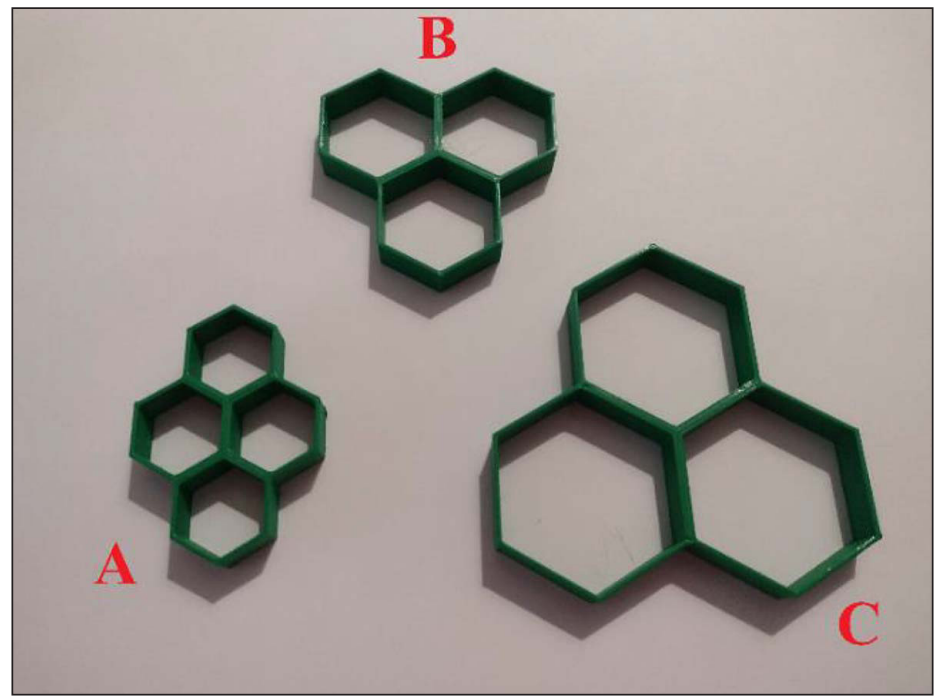

Fig. 4. Hexagonal honeycomb - circle inscribed: A - Ø20 mm, B - Ø30 mm, C - Ø40 mm

diameter of $\varnothing 30 \mathrm{~mm}$ and an internal opening of Ø20 mm (Fig. 5). The outer element of the beam, printed from PLA, is laminated with additional layers of carbon fibre in the place of connection with the frame, at the point where concentrated forces occur. Due to the production technology selected - 3D printing - the "cross brace" element consists of five parts. The support element is removable and bolted to the frame with screws.

The frame is laterally inclined by $15^{\circ}$ along the long sides of the B structure. This results from thesuspension geometry, which allows for running over obstacles larger than the wheel diameter, which in our case is $200 \mathrm{~mm}$. The smaller element of the suspension, the bogie connecting the wheels, rises high, and in certain settings the frame might rest on it. A drill tower is mounted on the front vertical wall so that the manipulator has free access and can pick up the drill bit with the soil sample. The drill is located in a laboratory container attached to the rear wall.

\section{NUMERICAL ANALYSIS}

The presented composite frame with sandwich-type walls was analysed using ANSYS Workbench 2020 R2. First-degree solid and shell elements were used in the analysis (Fig. 6).

The data on the materials used in the analysis of the frame come from the ANSYS Workbench library. Test samples were made simultaneously with the frame, in order to determine the actual material parameters such as density or equivalent Young's modulus. The tests conducted, which will be described in the next article, will be used for validating the model. The following frame loads were assumed for analysis (Fig. 7):

- point A - support,

- point B - support,

- point $\mathrm{C}$ - manipulator $200 \mathrm{~N}$ (due to the limited budget of the project and difficult to predict dynamic loads, a doubled force value was assumed),

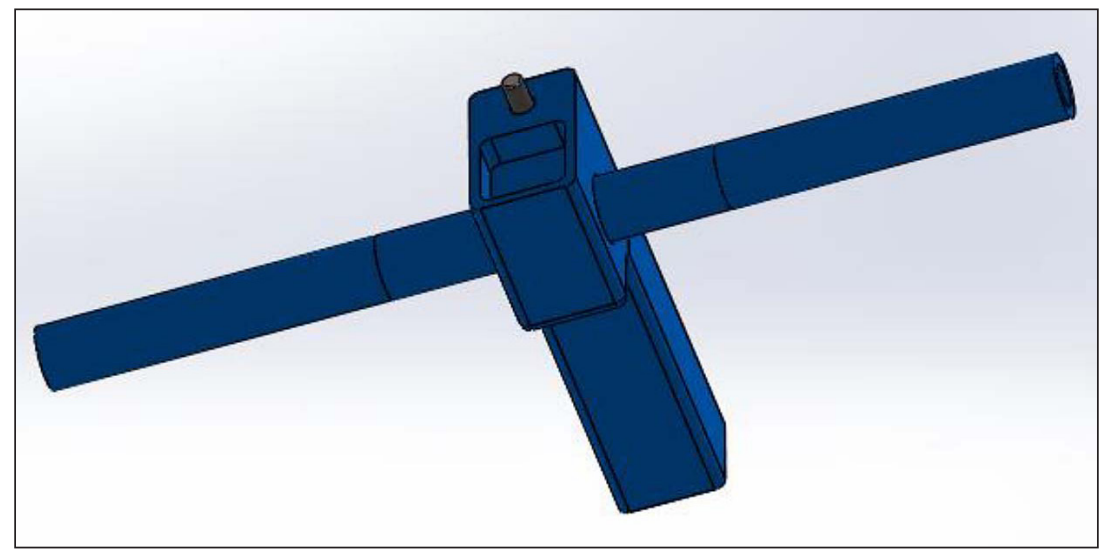

Fig. 5. Connecting element - "cross brace" 


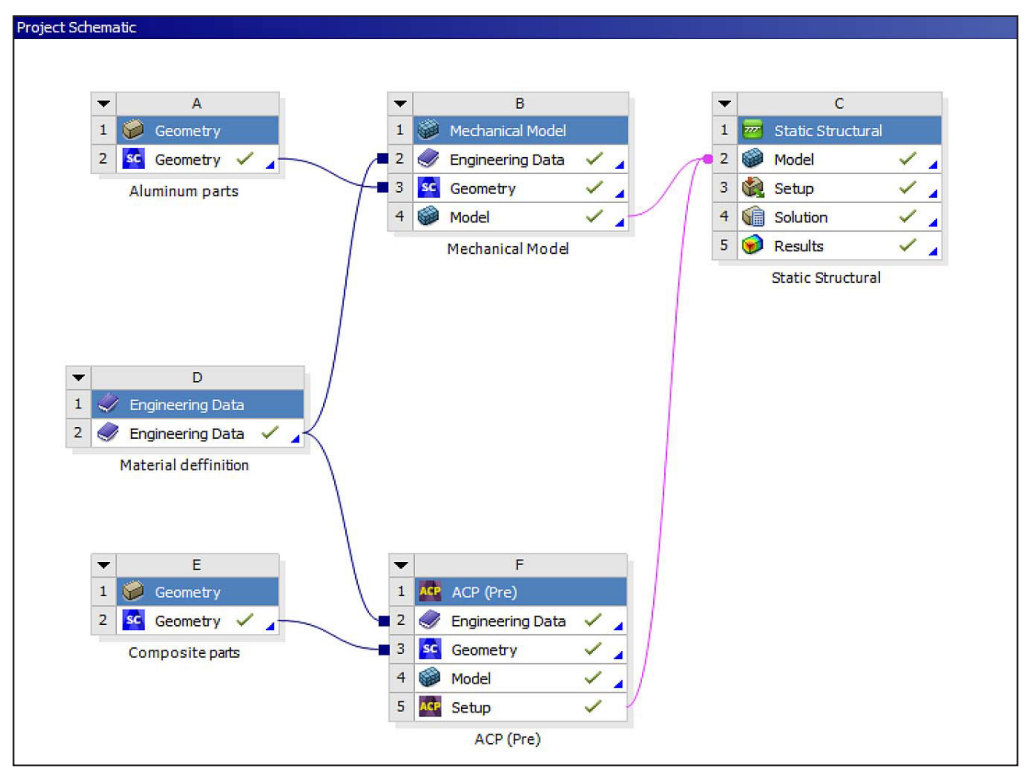

Fig. 6. A diagram of analysis in the ANSYS program

Table 1. Materials used in the analysis

\begin{tabular}{|c|c|c|c|}
\hline Parameter & Honeycomb-shaped core & Woven carbon fibre & Aluminium \\
\hline Density & $80 \mathrm{~kg} / \mathrm{m}^{3}$ & $1451 \mathrm{~kg} / \mathrm{m}^{3}$ & $2770 \mathrm{~kg} / \mathrm{m}^{3}$ \\
\hline Ex & $1 \mathrm{MPa}$ & $59,160 \mathrm{MPa}$ & \multirow{3}{*}{$71,000 \mathrm{MPa}$} \\
\hline Ey & $1 \mathrm{MPa}$ & $59,160 \mathrm{MPa}$ & \\
\hline Ez & $255 \mathrm{MPa}$ & $7,500 \mathrm{MPa}$ & \\
\hline$v X Y$ & 0.49 & 0.04 & \multirow{3}{*}{0.33} \\
\hline$v Y Z$ & 0.001 & 0.3 & \\
\hline$v X Z$ & 0.001 & 0.3 & \\
\hline GXY & $1 \mathrm{E}-06 \mathrm{MPa}$ & $3300 \mathrm{MPa}$ & \multirow{3}{*}{ 2.67E04 MPa } \\
\hline GYX & $37 \mathrm{MPa}$ & $2,700 \mathrm{MPa}$ & \\
\hline GZY & $70 \mathrm{MPa}$ & $2,700 \mathrm{MPa}$ & \\
\hline
\end{tabular}
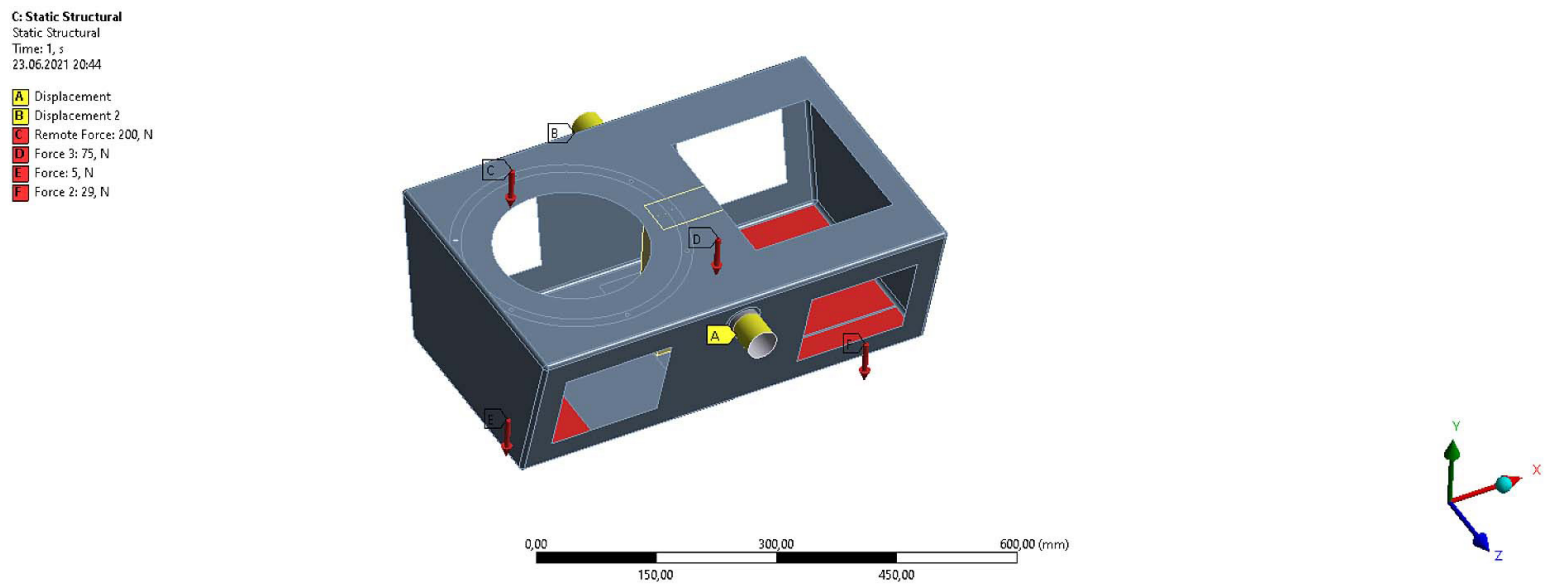

Fig. 7. Diagram of the structure mounting and loading

- point $\mathrm{D}$ - battery $75 \mathrm{~N}$,

- point $\mathrm{E}$ - computer and electronics $5 \mathrm{~N}$,

- point $\mathrm{F}$ - laboratory $29 \mathrm{~N}$.
The analysis was performed for several variants of the grid in order to verify the convergence of the results. The similarity of the obtained 
Table 2. Densification of the grid

\begin{tabular}{|l|c|c|c|}
\hline Number of nodes & 12319 & 10083 & 8537 \\
\hline Number of elements & 11786 & 9572 & 7993 \\
\hline $\begin{array}{l}\text { Maximum reduced stresses } \\
\text { [MPa] }\end{array}$ & 25.869 & 25.858 & 25.785 \\
\hline Safety factor [-] & 11.44 & 11.45 & 11.46 \\
\hline
\end{tabular}

results confirms the appropriate densification of the grid (Table 2). The analysis was carried out iteratively, starting from the base load value up to the dangerous load value (Table 3 ).

The following drawings presented (Fig. 8, Fig. 9, Fig. 10) show the results for the analysis without force multipliers. Figures 11, 12, and 13 shows the results for the analysis with the critical load included.
Figure 14 show where the frame joins the rocker-bogie suspension beam. It is possible to identify the point where the reduced stresses reach a value close to the hazardous value for the material used in the structure. Due to the complex state of stresses occurring in this point, potentially dangerous for the structure, additional local laminate layers should be applied to increase the durability of the structure. Figure 15 show the progress of changes in the value of reduced stresses as a function of the force multiplier and the safety factor as a function of the force multiplier. Despite the linear increase in load, a non-linear decrease of the safety factor can be observed, which may result from the change in the relationship between the values of shear stresses and the values of normal stresses.

Table 3. Results of the analysis

\begin{tabular}{|l|c|c|c|c|c|c|c|c|c|c|}
\hline Force multiplier [-] & 1 & 1.1 & 1.2 & 1.3 & 1.4 & 1.6 & 1.8 & 2 & 2.2 & 2.4 \\
\hline Force D & -5 & -5.5 & -6 & -6.5 & -7 & -8 & -9 & -10 & -11 & -12 \\
\hline Force B & -29 & -31.9 & -34.8 & -37.7 & -40.6 & -46.4 & -52.2 & -58 & -63.8 & -69.6 \\
\hline Force C & -75 & -82.5 & -90 & -97.5 & -105 & -120 & -135 & -150 & -165 & -180 \\
\hline Remote force A & -200 & -220 & -240 & -260 & -280 & -320 & -360 & -400 & -440 & -480 \\
\hline Maximum reduced stresses [MPa] & 25.9 & 28.5 & 33.9 & 41.4 & 44.5 & 50.9 & 57.3 & 63.6 & 70 & 76.3 \\
\hline Safety factor [-] & 11.4 & 10.4 & 8.7 & 7.1 & 6.5 & 5.8 & 5.1 & 4.6 & 4.2 & 3.8 \\
\hline
\end{tabular}
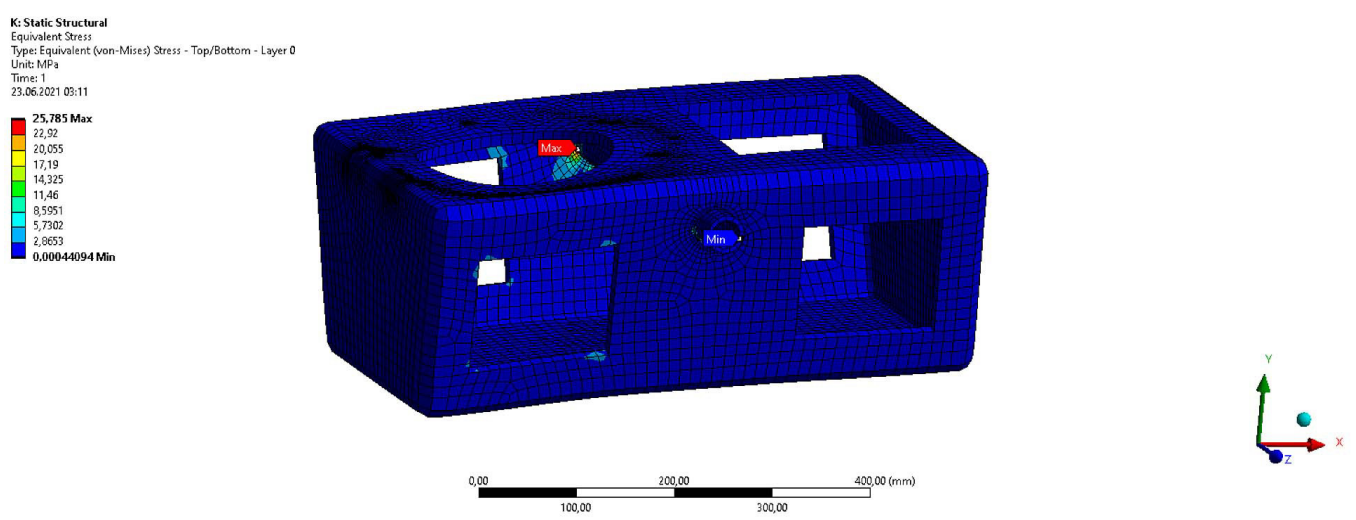

Fig. 8. Maximum reduced stresses for the base load


Fig. 9. Total displacements for the base load 

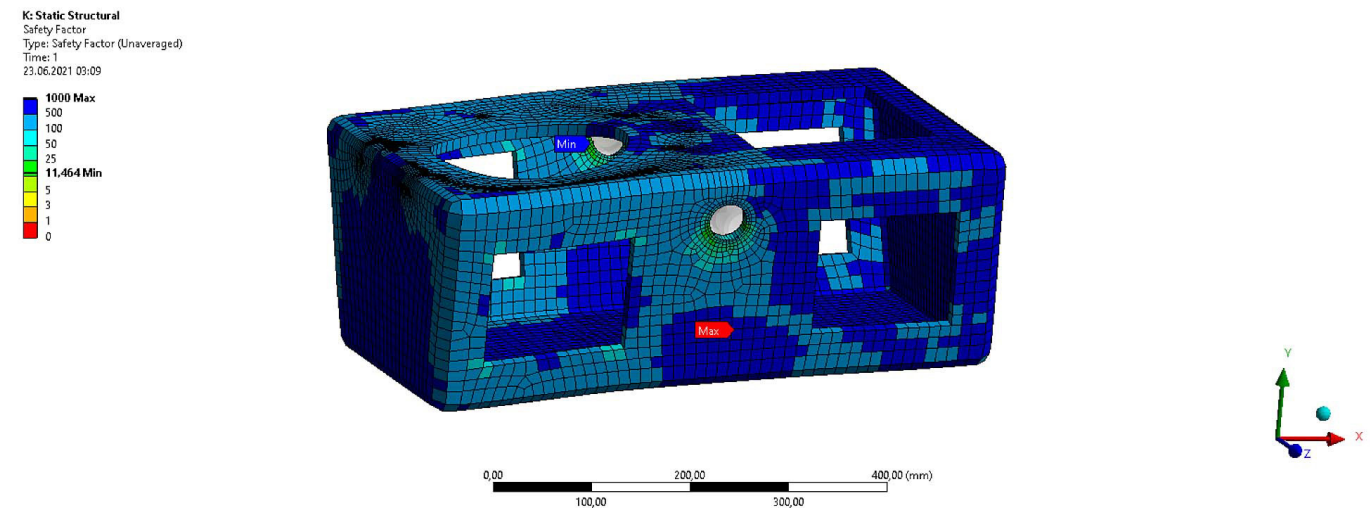

Fig. 10. Distribution of the safety factor for the base load
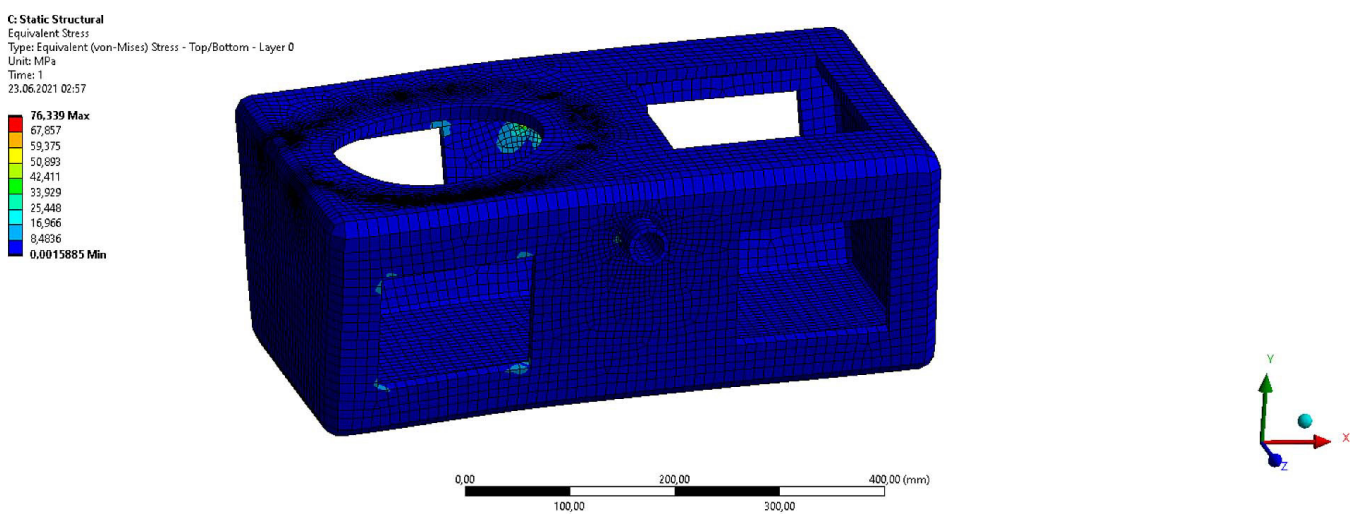

Fig. 11. Maximum reduced stresses for the load with a hazardous multiplier
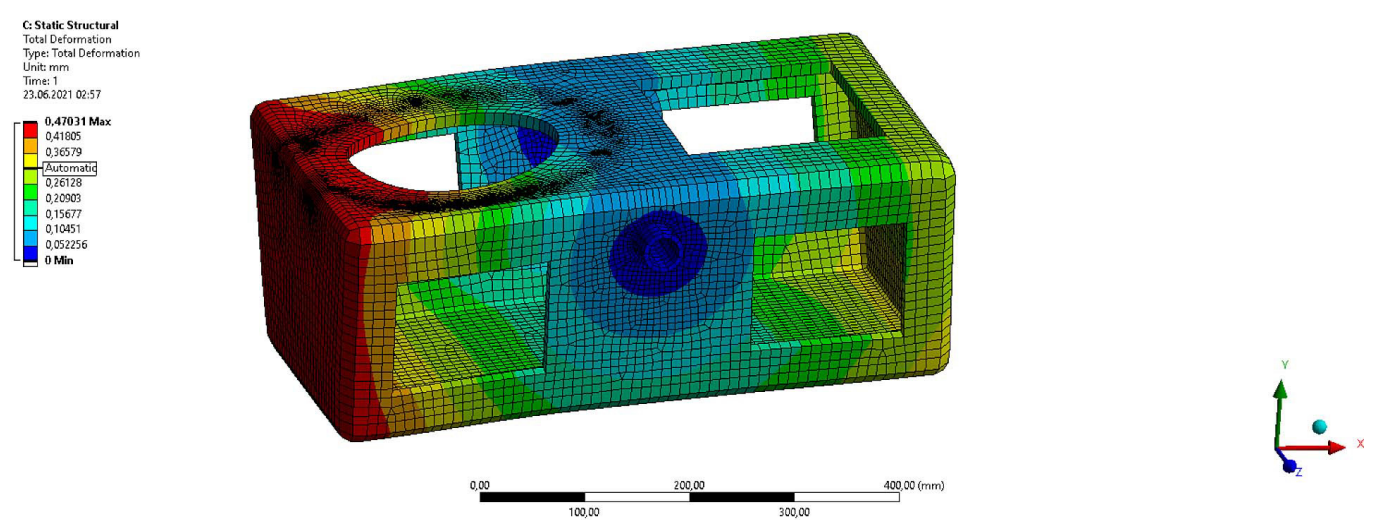

Fig. 12. Total displacements for the load with a hazardous multiplier
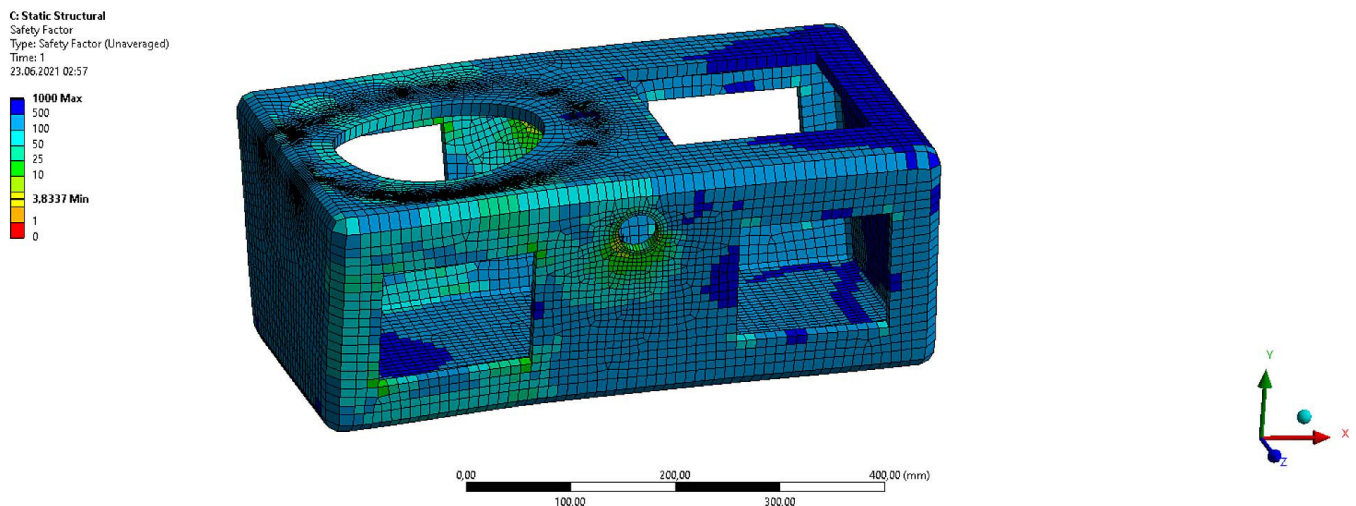

Fig. 13. Distribution of the safety factor for the load with a hazardous multiplier 


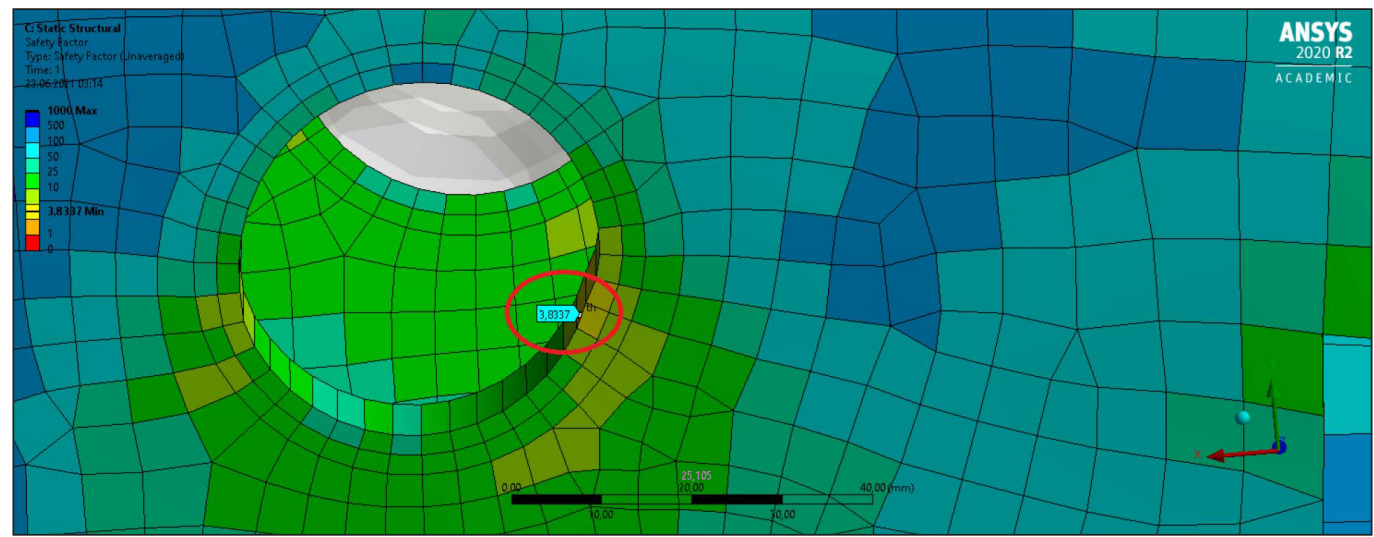

Fig. 14. Close-up of the critical point in the structure, potentially damaged place according to the Tsai-Hill hypothesis

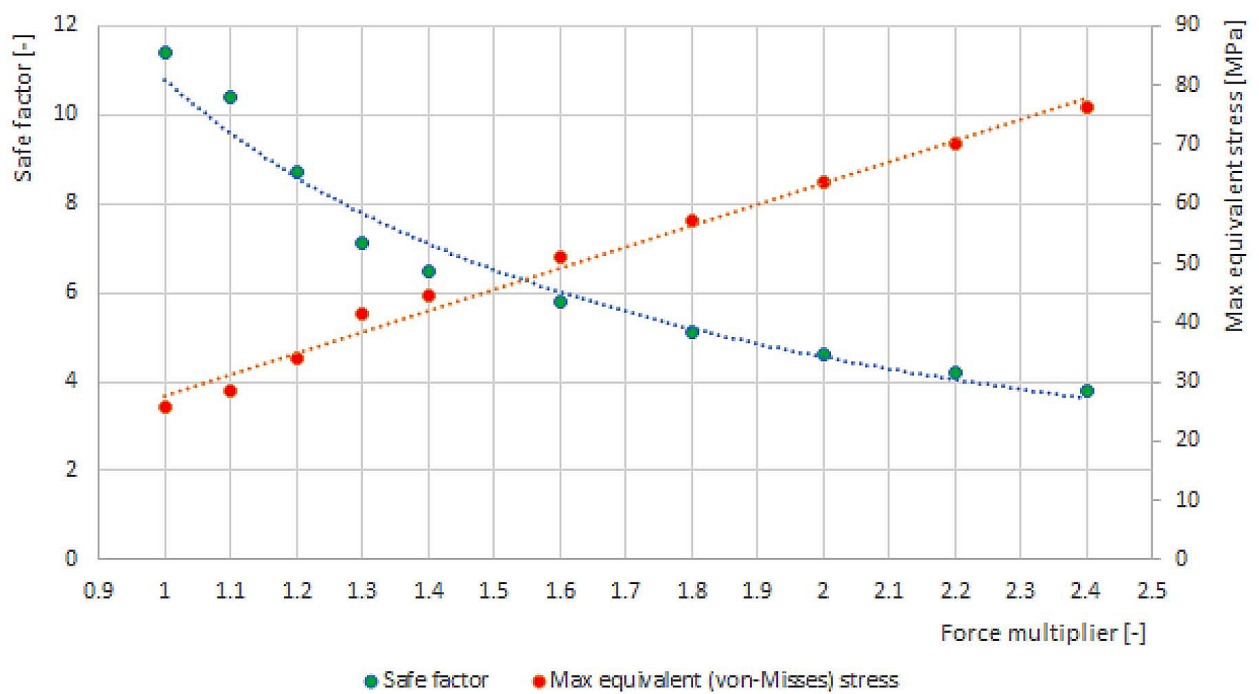

Fig. 15. The curves of the safety factor and reduced stresses as a function of the loads multiplier

\section{CONCLUSIONS}

The frame presented in the article is part of a larger project, involving the participation of the Martian rover designed by the Bekker Team Science Club at the Faculty of Automotive and Construction Machinery Engineering of the Warsaw University of Technology in the European Rover Challenge. It should be emphasized that the project is financed from the $\mathrm{KN}$ budget and is a low-budget one. It was possible to attain the adopted goals, i.e., the design and manufacture of a lightweight frame for a rocker-bogie type suspension. The frame meets all the criteria, the selected technology matches the manufacturing capabilities of the students at the workshop of the Faculty of Automotive and Construction Machinery Engineering in pandemic conditions. The materials used are readily available and the results obtained are satisfactory. In the future, the club members will manufacture rocker-bogie suspension profiles using a technique combining 3D printing and carbon composite to further optimize the design in terms of vehicle weight. The growing interest in vehicles of this type is the beginning of the "Martian motorization".

\section{REFERENCES}

1. Batko W., Dąbrowski Z. Nowoczesne metody badania procesów wibroakustycznych (zastosowania techniczne) p. II, ITE - PIB, 2006.

2. Bielawski R., Rządkowski W., Kowalik M., Kłonica M. Safety of aircraft structures in the context of composite element connection. International Review of Aerospace Engineering(I.RE.AS.E). 2020;13(5):159- 
164. DOI: 10.15866/irease.v13i5.18805

3. Boczkowska A., Krzesiński G. Kompozyty i techniki ich wytwarzania. Oficyna Wydawnicza Politechniki Warszawskiej. Warszawa; 2016.

4. Buckley J.D., Edie D.D. Carbon - Carbon Materials and Composites. Noyes Publications; 1993.

5. Dąbrowski H., Wstęp do mechaniki materiałów kompozytowych, 1989.

6. Gryz K. Engineering thesis - A concept of a special vehicle's manipulator. Warszawa; 2021.

7. Kapuściński J. Projektowanie i technologia materiałów kompozytowych; 1983.

8. Karczmarzyk S. Modelowanie komputerowe w praktyce inżynierskiej. Statyczny model prostokątnej płyty typu sandwich; 2018.

9. Kłonica M., Bielawski R. Strength of Joints with "Hi-Lok" Fasteners in Aircraft Safety Considerations. Advances in Science and Technology Research Journal. 2019;13(4):87-93. DOI: $10.12913 / 22998624 / 114179$

10. Kurnik W., Tylikowski A. Mechanika elementów laminowanych; 1997.
11. Leda H. Kompozyty polimerowe z włóknami ciągłymi; 2006.

12. Markuszewski D. Comparison of various types of damage symptoms in the task of diagnostic composite profiles. Diagnostyka. 2019;20(3):105-110. DOI 10.29354/diag/111799

13. Podembski K., Suspension - internal materials of KN Bekker Team.

14. Sclater N., Chironis N.P. Mechanisms and mechanical devices sourbook; 2011.

15. Skórski W., Zawisza M. Influence of the composite modification of the wooden wing skin of the glider on deflection lines and resonance vibrations. Polimery. 2019;64(4):267-271.

16. Vasiliev V.V., Morozov E.V. Advanced Mechanics of Composite Materials. Elseviere; 2007.

17. Wilczyński A.P. Polimerowe kompozyty włókniste. WNT; 1996.

18. https://roverchallenge.eu/en/publishing-the-ercpro-rules-and-the-erc-student-rules-update/

19. https://spidersweb.pl/autoblog/perseverance-opportunity-spirit-lazik-marsjanski/ 